\title{
The Role of Sublexical Variables in Reading Fluency Development among Spanish Children
}

\section{(Sublexical Variables in Reading Fluency)}

Marta Álvarez-Cañizo ${ }^{1 *}$, Paz Suárez-Coalla ${ }^{1}$, Fernando Cuetos $^{1}$

${ }^{1}$ Departament of Psychology, University of Oviedo, Asturias, Spain

*Marta Álvarez-Cañizo,

alvarezcanmarta@uniovi.es

Department of Psychology, University of Oviedo, Pza Feijóo s/n, Oviedo 33003, Spain

\section{Abstract}

Several studies have found that after repeated exposure to new words, children form orthographic representations that allow them to read those words faster and more fluently. However, these studies did not take into account variables related to the words. The aim of this study was to investigate the influence of sublexical variables on the formation of orthographic representations of words by Spanish children. The first experiment used pseudowords of varying syllabic structure and syllabic frequency. The stimuli for the second experiment were formed with or without context-dependent graphemes. We found that formation of orthographic representations was influenced by syllabic structure (easier for words with simple syllabic structure) and the context-dependency of graphemes (easier in the absence of context-dependent graphemes), but not syllabic frequency. These results indicate that the easier it is to read a word, the easier it is to form an orthographic representation of it.

Keywords: reading learning, orthographic representations, syllabic frequency, syllabic structure, context-dependent graphemes, transparent orthography. 